\title{
Leaders' Career Development for Sustainability: Lithuanian Case
}

\author{
Nijole Petkeviciute ${ }^{1}$ Dr.; Asta Balciunaitiene ${ }^{2}$ Dr. \\ Vytautas Magnus university, Lithuania \\ Nijole.Petkeviciute@vdu.1t ${ }^{1}$; Asta.Balciunaitiene@vdu.1t²
}

\begin{abstract}
Leaders' career development for sustainability in organizations of Lithuania will be discussed in the paper. The potential of organization to create favourable working environment suitable for cooperation, communication and networking to combine different actions is based on leader's awareness about sustainability. Moreover, sustainability stipulates organizations to change leaders' behaviour for communicating their ideas that make profitable solutions. Therefore, it is significant to raise leaders' career development and sustainability understanding as it might equip leaders with special skills and knowledge to make adequate decisions for successful collaboration and efficient results in sustainability context. The paper aims to explore that it is necessary to raise awareness about sustainability in organizations that leaders would be able to set clear future visions, create positive relationship between staff, communicate sustainability ideas in organizations and to find out some barriers that leaders are facing. For this reason, it is highly important that leaders envisage how to develop their career for sustainability and make efforts to motivate employees to work at their full potential. Research problem - leaders lack sufficient knowledge about sustainability and influence on their career development in organizations of Lithuania. Research methods -scientific literature analysis, qualitative data collection (interview) and analysis. The results of the study demonstrate that employees do not have enough understanding about sustainability and leaders lack knowledge about opportunities for career development in organizations of Lithuania.
\end{abstract}

Keywords: awareness of sustainability, employees, leaders, career development.

\section{Introduction}

The term sustainability is very broad and encompasses many areas of expertise. More and more corporate businesses are including sustainability into their management agendas as it is useful for staff career development. This enables researchers to discuss and elaborate the connection or link between sustainability and other systems, like human resource management, employees' education and career development (Savanaviciene, Stankeviciute, 2014; Human resources today, 2018). Sustainability for organizations on a daily basis demonstrates their activities in support of the new initiatives in the working environment, transparency and staff training. Sustainability and activities for each employee have a direct impact on the development of their career. Analysis of scientific literature and documents (Streimikiene, 2014; Wiek, Iwaniec, Childers, 2014) on sustainability concept stating its practical realization, conceptualization of social needs and values emphasize the significance of sustainability in organizations. The direction towards the value - based priorities in sustainability orientated society marks the shift of leaders' needs. Constant changes happening in modern society are a response to societal transformations, and one of its peculiarities lies in that organizations urge to discuss leaders' career development focusing on the approach of sustainability concept. Although there are many interpretations about the concept of sustainability and its implementation in organization, there is mutual consensus about the following three principles (Wiek, Iwaniec, Childers, 2014):

- insurance of equality and fairness for leaders and staff to achieve their goals in life;

- leaders and staff empowerment to believe in their abilities and to make positive changes;

- leaders and staff personal commitment to take part in finding solutions to social problems.

Authors (Gudykunst, 2005; Streimikiene, 2014; Urdzina-Merca, Dislere, 2018) emphasize the importance of the working environment, relationships, information technologies and communication. Rapidly changing information and communication technologies and their use enables leaders to have access to newest information, to take part in webinars, forums and go-to-meetings on-line, which allows staff involvement. Therefore, it could be claimed that the greatest leader's responsibility is to motivate and inspire staff to go forward.

Some researchers (Gudykunst, 2005; Petkeviciute, 2013) indicate that the changes in the last decades of intense economic, social, technological, sustainability values have fundamentally altered the nature of 
the work itself: many organizations provide the guarantee of a fixed and continuous employment and ensure a stable career development opportunity for its employees. Previously traditional leaders' career, perceived as vertical progress in one organization, at the moment is becoming more horizontal and greater responsibility for the career development depends on individual efforts. It could be said that leaders' career development is a complex personal process, which is conditioned by a number of factors including sustainability. Leaders in organizations claim that they need more training about sustainability so that they could make adequate decisions which increase employees' motivation.

Therefore, reports of sustainability (Sustainability Reporting in.., 2016) is a driver of organization's sustainability impact, which makes it even more important for the organizations to report when and how they establish their sustainability process (Schaltegger, Wagner, 2006). In order to do this, leaders in organizations have to control, assess and measure different operations as well as evaluate employees' career development (Schiehle, Wallin, 2014).

As the study is based on ideas of positivist paradigm which emphasizes the progress of humanity ruled by order and harmony, modern humanistic philosophy focusing on human functioning without prejudices and discrimination as well as holistic approach to individual's abilities, needs, expectations and actions, reporting about sustainability corresponds with the philosophical background. Moreover, the study embraces approaches of constructivist theory, specifically social constructivism with its ideas that a leader can reconstruct knowledge-based models and motivate other employees for vertical and horizontal career development which appears in the socially conditioned environment (Chiu, 2003).

Leader's modern career is mainly associated with the personal development in different areas of life: education, employment, family life, social activities, thus, the personal career emphasizes self-cognition, self-education, more opportunities to get to know and to express themselves. It depends on the individual's aspirations, opportunities and objectives. Higher sustainability awareness empowers leaders, not only to be sustainable in professional activity, in personal career development, but everyday life, too. The success of personal career depends on how much leaders' understanding about sustainability is developed (Petkeviciute, 2013).

For this reason, more and more organizations in Lithuania are working proactively and are setting their priorities and plans for employees' training in order to construct their careers towards sustainability (Nakrosis, Vilpisauskas, Jahn, 2016). They are communicating this through the media about the progress of implementation of their action plans on sustainability. Moreover, organizations are changing and developing values adequate to the new era of sustainable development and train their staff to think strategically, to work and act effectively in sustainability context.

It is significant to consider how leaders are trained, which the important proofs are and how the process quality is maintained. Awareness about sustainability provides leaders with better career opportunities and higher professional recognition by their organizations and colleagues.

Sustainability awareness determines the level of knowledge, skills, competencies and qualities leaders should have in order to have sustainability approach towards their job, team relations, training and career development. Their actions should contribute to the decision-making efficiency and add value to their organizations. Thus, the application of the sustainability approach by the leaders will have the following positive effects for the relations with the local and global environment: reduction of energy resources, recycling, using public transport, cycling to work place; saving human potential and energy; improving social climate around the ethical stakeholders and the local organizations increasing level of public welfare.

The value of sustainability is beneficial for all sides - the employees, leaders and organizations. The benefits for the leaders can be defined in several aspects: through the sustainability approach and career development. Leaders improve reputation and business activities; their actions lead to the reduction of energy, human resources costs and provide added value to their organizations. From that point of view sustainability importance and influence, for the performance of the leaders and the success of their organizations are extremely significant. Leaders could know about possibilities of development of their career raising deeper understanding about sustainability concept and its implementation in organizations. Also, it could be claimed that higher awareness of sustainability could enhance vertical and horizontal leaders' career which is profitable for all segments in organizations. 
The paper aims to explore that it is necessary to raise awareness about sustainability in organizations that leaders would be able to set clear future visions, create positive relationship between staff, communicate sustainability ideas in organizations and to find out some barriers that leaders are facing.

\section{Methodology}

The purpose of the study highlights the importance of leader's career development for sustainability and to motivate employees to work at their full potential. Research problem - leaders lack sufficient knowledge about sustainability and influence on their career development in organizations of Lithuania.

Research methods - scientific literature and documents analysis, qualitative data collection (interview) and analysis of the study results. The results of the study demonstrate that employees do not have enough understanding about sustainability and leaders lack knowledge about opportunities for career development in organizations of Lithuania.

In order to analyse leaders' career development for sustainability, qualitative research methodology (interview) was used. Qualitative research method enables to collect various information about the research object and phenomenon helps to discover original facts which are useful for interpretation and discussion. In scientific field (Rupsiene, 2007) this method is applied to interpret a phenomenon, to understand problems and reveal causes. It is also used for scientific discussion. The qualitative research method (interview) of the study was applied to find out about respondents' experiences and reflection. The interview was planned and organized in a particular environment (university) with the aim to investigate respondents' problems and to analyse their needs.

Based on scientific literature, it was designed the research instrument - a questionnaire for interview which was used to reveal the needs of leader's career development for sustainability There were seven 9 interview topics. All topics of the questionnaire correspond with the concept of sustainability and leaders' career development.

The topics of the interview are the following:

1. Statement which disclose awareness of sustainability.

2. Statements which disclose opinion about importance of sustainability for industry.

3. Statements which disclose the importance of sustainability in organization.

4. Statements which disclose the importance of sustainability for employees.

5. Statements which disclose main barriers for implementation of sustainability.

6. Statements which disclose measurement of sustainability in organization.

7. Statements which disclose the five most urgent reporting strategies to undertake for sustainability in organization.

8. Statements which disclose the definition of sustainability leader.

9. Statements which disclosure sustainability competences for leaders' career development.

Respondents. Qualitative (interview) research was performed in 2017. There were 7 different level managers of organizations in Lithuania (private and public), who took part in the interview and expressed their opinions about seven topics. The majority of participants $(87 \%)$ who took part in the survey were in the first level leaders, the smallest number were in the top management $(0.5 \%) .67 \%$ of participants were $35-45$ years old and $33 \%-45-55$ years old. The distribution of respondents according their gender was: male $-75 \%$ and female $-25 \%$.

\section{Results and Discussion}

The analysis of the results of interview are presented below. The research revealed that the biggest number of the respondents from the private $(45.8 \%)$ and from the public organizations $(54.2 \%)$ have heard something about sustainability but have no clear ideas what the concept means. Leaders' knowledge about the sustainability might help to create sustainable relationship between leaders and employees in organizations in Lithuania.

Leaders could share most of the ideas about sustainability and career development. Generalizing, it could be claimed that respondents of private and public organizations do not have influence on sustainability concept. The majority of the respondents said that their organization has no formal 
sustainability department or manager, and only a few organizations have a concerned person who is dealing with those problems.

The first question was about the meaning of the word 'sustainability'. Most respondents related sustainability to: "good health and well-being ( $87 \%)$; partnership for the goals in personal life (26\%); responsible consumption and production (67\%); employment and economic growth (47\%); education $(33 \%)$; environmental protection $33 \%)$; professional life - sustainable internal and external communication; planning of the future; gender equality; water and sanitation. welfare, security for all staff and nature protection" (Figure 1).

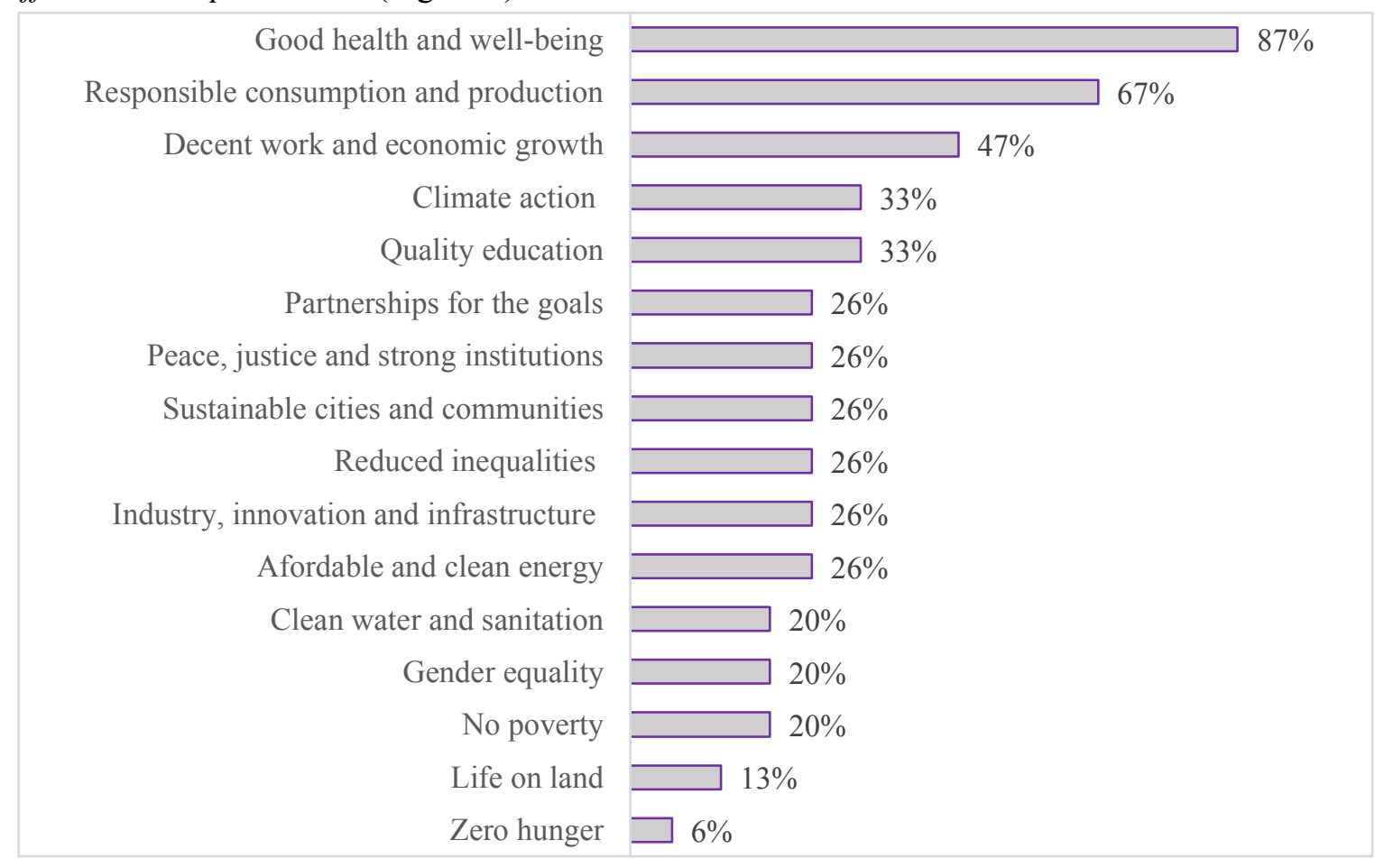

Figure 1. Criteria of sustainability based on respondents' answers.

The second question was about the importance of sustainability for leader's industry in general. The respondents marked: that it is "Very important, because it connects all aspects of activities; encourages development and protects natural resources".

In response to the third question, of why it is important to implement sustainability in your organization, the respondents pointed out that it is useful for: "Work experience; Communication skills; Financial skills; Understanding of sustainability; Leadership skills; Innovation skills; Long-term planning skills; Empathy", but it was signified of immense value Understanding of sustainability and Communicating about sustainability.

The fourth question was about reflection of employee's experiences about the main advantages of implementing sustainability. The respondents claimed that it helps for development of "Sense of community; Tolerance; Smooth communication; Environmental protection; Financial benefits; Better future for generations; Improving the image of the organization; New markets; Innovations". In response to the fifth question about the main barriers for implementing sustainability, the respondents identified the following obstacles "Lack of finance, time and information; Lack of staff; Poor communication; Egoistic attitude; Instability of market". In response to the sixth question about sustainability measurement the respondents noted that "There is no measurement of sustainability" in participating organizations. The seventh question asked respondents to point out five most urgent reporting strategies about sustainability in organization. The respondents signified the following strategies according to their importance:

- "organize a survey on current state in the company;

- prepare a strategy and action plan;

- increase finance sources intended to support sustainability;

- attend professional training;

- hire a consulting agency and outsourcing experts". 
In response to the eight question about sustainable leaders the respondents characterized them as: "Sustainable leader is the person who aims to develop sustainability in organization, who is a good communicator trying to inspire others".

In response to the last question about the competencies of sustainability needed for leaders' career development, the respondents marked: "Sociability; Education; Experience; Good relations with stakeholders; Insight; Continuous improvement; Initiative; Global and holistic thinking, Respect to nature".

As the aim of the study was to find out that there are some barriers that leaders are facing. It was mentioned that there is a lack of communication, finances, competent staff, and dominate egoistic and individualistic attitudes. So, it would be useful to organize staff training about advantages of sustainability and impact on career development.

Respondents determined that for sustainability dissemination leaders need some competencies such as: good relations with stakeholders; insight; initiative; global and holistic thinking, respect to nature. There is a need for more training for workers on the concept of sustainability.

Leaders' career development can be defined as a combination of motives, values and talents that influence an individual's career choices. The survey showed that awareness about sustainability is the most important for leaders' career development. It is inevitably focused on the horizontal and vertical career what drives the individual. The importance for leader's career development is the recognition that there are strong sustainability competencies which affect career satisfaction, and career orientations provide a way of understanding sustainability motivators of career development. Many organizational career programmes assume that employees are motivated by the prospect of promotion, but there is considerable evidence for differences in motivation (Holland, 1985). Although, equally, there is evidence to suggest that employee's promotion aspirations in sustainability are often underestimated.

If employees remain in a job that is not congruent with their career development and repress their motivations, it is argued that they seek to achieve the missing elements of their career through outside work interests or by withdrawing commitment, which has obvious implications for organizations.

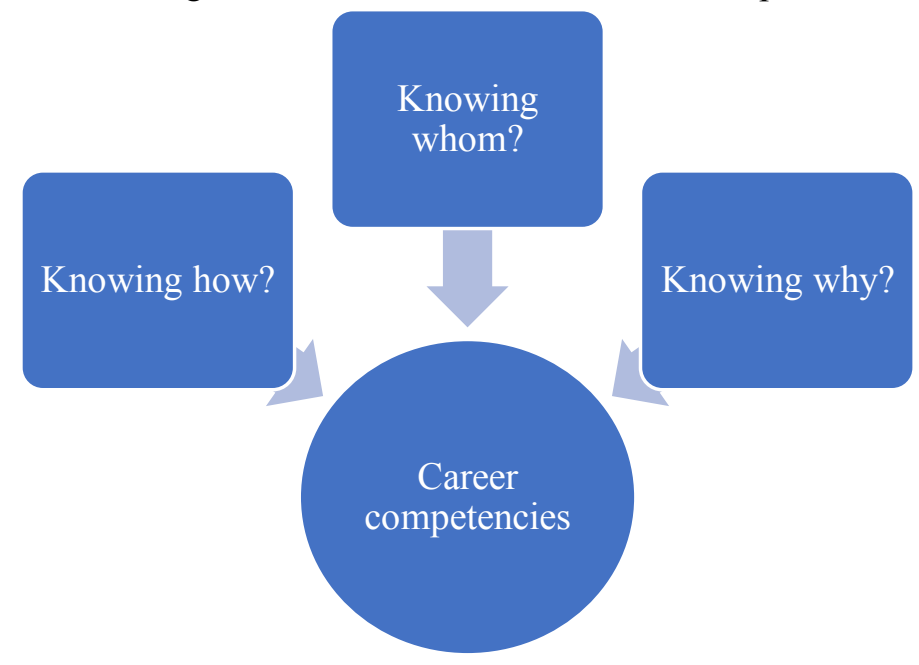

Figure 2. Leaders' career competencies for sustainability.

Leaders' career competencies for sustainability could be divided into three areas. knowing whom; knowing how; knowing why (Figure 2). Indeed, there is, knowing how competencies are about finding sustainability related knowledge, such as what's needed to perform well for environment and soft skills. Understanding this can help the leaders focus their career development in sustainability more accurately. Then knowing why competencies are about understanding sustainability concept and the values, meanings and interests that leaders could hold for environment protection, global warming and organizational involvement. Also, it is important to develop the confidence, motivation, enthusiasm and self-assurance needed to progress on sustainability. Finally, knowing whom is about identifying the key players that determine success in sustainability and gaining proximity to the employees that can aid development, such as through more effective networking. This approach can be a useful frame for high potentials trying to understand how to work on sustainability for leaders' career development. Typically, organizations will support the development of career competencies for sustainability by making some 
of the core tools and techniques available, or by providing training in sustainability aspects, such as communication, networking and sustainability awareness.

Leaders' career core competencies can have immense value both to organizations and to employees in understanding benefits in sustainability:

- a way of structuring career discussions and organizing interviews about sustainability;

- better understanding by leaders of why sustainability drives for their career development;

- the ability to create more sustainable organizational design;

- increased career satisfaction through more constructive discussions with employees about sustainability;

- the design of appropriate reward systems using sustainability concept;

- the design of appropriate leaders' promotion systems.

In order to work effectively, there must be sufficient trust in the organization that questionnaires or interviews will be conducted in good faith, that the views of the person are accurately reflected. Some authors did research in career development (Yarnall, 2008) and found that there can be immense value in using the collective results of an organizations career profile, to get a greater insight into the career culture of the company (Sustainability and Reporting..., 2015). At the same time, it would be useful to embed sustainability approach into employees' career development culture.

\section{Conclusions}

The study is based on ideas of positivist paradigm which emphasizes the progress of humanity ruled by order and harmony, modern humanistic philosophy focusing on human functioning without prejudices and discrimination as well as holistic approach to individual's abilities, needs, expectations and actions, reporting about sustainability corresponds with the philosophical background.

The results of the qualitative research (interview) showed that respondents' understanding of sustainability is as follows "good health and well-being ( $87 \%)$; partnership for the goals in personal life (26\%); responsible consumption and production (67\%); employment and economic growth (47\%); education (33\%); environmental protection (33\%)". So, they place higher emphasis on personal good health and wellbeing.

It was mentioned by respondents that financial skills are very significant in the development of sustainability concept in organizations in Lithuania.

Most of respondents assume that there's a lack of sustainability consistency in their organization and it is only secondary marketing thing as well as there's not enough information about that. Moreover, there is a lack of evidence of sustainability measurement elements. The majority of the respondents said that their organization has no formal sustainability department or manager, and only a few organizations have a concerned person who is dealing with those problems, also there are some barriers that leaders are facing: a lack of communication, finances, competent staff, and dominate egoistic and individualistic attitudes.

The research revealed that the biggest number of the respondents from the private $(45.8 \%)$ and from the public organizations $(54.2 \%)$ have heard something about sustainability concept but have no clear ideas what it means. Leaders' knowledge about the sustainability might help to create sustainable relationship between leaders and employees in organizations in Lithuania.

The study demonstrated that awareness about sustainability is the most important for leaders' career development. It is inevitably focused on the horizontal and vertical career what drives the individual.

Sustainability for the respondents is an important factor in their organizations, and they identified a number of key advantages of sustainability concept development in organizations.

Leaders' career competencies for sustainability could be divided into three areas: knowing whom; knowing how; knowing why. Knowing how competencies are about finding sustainability related knowledge. Knowing why competencies are about understanding sustainability concept and the values, meanings and interests. Knowing whom is about finding the right team for successful implementation of sustainability. This strategy could be a useful tool for increasing sustainability awareness in organizations and for leaders' career development. 


\section{Bibliography}

1. Chiu L.F. (2003). Transformational potential of focus group practice in participatory action research. Action Research, 1(2), 165-183.

2. Gudykunst W. B. (2005). An Anxiety/Uncertainty Management (AUM) Theory of Effective Communication: Making the Mesh of the Net Finer. In W.B. Gudykunst (Ed.), Theorizing about Intercultural Communication. London: Sage Publications, 281 - 323.

3. Holland J.L. (1985). Making Vocational Choices: A Theory of Careers. Englewood Cliffs, NJ: Prentice-Hall.

4. Human resources today. (2018). Retrieved from: https://www.humanresourcestoday.com/careerdevelopment/talent-management/

5. Nakrosis V., Vilpisauskas R., Jahn D. (2016). Lithuania Report - Sustainable Governance Indicators. Gutersloh Germany: Bertelsmann Stiftung. Retrieved from: http://www.sginetwork.org/docs/2016/country/SGI2016_Lithuania.pdf

6. Petkeviciute N. (2013). Career Management: organizational perspective. Kaunas: VDU.

7. Rupsiene L. (2007). Methodology of collecting qualitative research data. Klaipeda: KU.

8. Savanaviciene A., Stankeviciute Z. (2014). The Disclosure of Sustainability and Human Resource Management Linkage. Human Resources Management and Ergonomics, 8(1), 88-104. Retrieved from https://frcatel.fri.uniza.sk/hrme/files/2014/2014_1_07.pdf

9. Schaltegger S., Wagner M. (2006). Managing Sustainability Performance Measurement and Reporting in an integrated manner. In: S. Schaltegger, M. Bennet, R. Burrit (Eds.), Sustainability Accounting and Reporting. Dordrecht: Springer, 681-697.

10. Schiehle T., Wallin J. (2014). The reporting on sustainability performance indicators. Umea: Umea School of Business and Economics. Retrieved from: http://www.divaportal.se/smash/get/diva2:732792/FULLTEXT01.pdf

11. Streimikiene D. (2014). Sustainable Development: Theory and Practice. Kaunas: VU.

12. Sustainability and Reporting Trends in 2025: Preparing for the Future. (2015). GRI's Reporting 2025 Project: First Analysis Paper. Amsterdam, The Netherlands: Global Reporting Initiative. Retrieved from: https://www.globalreporting.org/resourcelibrary/Sustainability-and-ReportingTrends-in-2025-1.pdf

13. Sustainability Reporting in the European Union - Policy Developments. (2016). Retrieved from: https://www.globalreporting.org/information/policy/Pages/EUpolicy.aspx

14. Urdzina-Merca I., Dislere V. (2018). Information and Communication Technology Based Career Guidance Model for Young People. In V. Dislere (Ed.), The Proceedings of the International Scientific Conference Rural Environment, Education, Personality (REEP-2018), 11. Jelgava: LLU TF, 406-415. Retrieved from:

http://llufb.1lu.lv/conference/REEP/2018/Latvia_REEP_2018_proceedings_ISSN2255808X.pdf

15. Wiek A., Iwaniec D. M., Childers D. L. (2014). Studying, teaching and applying sustainability visions using systems modelling. Sustainability, 6(7), 4452-4469.

16. Yarnall J. (2008). Strategic Career Management: Developing Your Talent. Oxford: Elsevier Ltd. 